\title{
Path Analysis of the Related Factors to Subjective Well-Being of Primary and Middle School Principals-Based on Job Demands-Resources Model
}

\author{
Chunmei Hu${ }^{1,2 *}$, Shujing Cui ${ }^{1,2}$, Huamin $\mathrm{He}^{1,2}$ \\ ${ }^{1}$ College Education, Chongqing University of Arts and Sciences, Chongqing, China \\ ${ }^{2}$ Laboratory of Cognition and Mental Health, Chongqing University of Arts and Sciences, Chongqing, China \\ Email: "hhm6666@163.com
}

Received 19 February 2016; accepted 21 March 2016; published 24 March 2016

Copyright (C) 2016 by authors and Scientific Research Publishing Inc.

This work is licensed under the Creative Commons Attribution International License (CC BY).

http://creativecommons.org/licenses/by/4.0/

(c) (i) Open Access

\begin{abstract}
Objective: The objective was to investigate path analysis of work-family conflict, job salary and promotion satisfaction, job burnout to subjective well-being of primary and middle school principals, and provide advices for enhancing their subjective well-being. Methods: Totally 300 primary and middle school principals in Chongqing completed the WFC, JSPSS, MBI-GS and GWB. Results: There were four significant paths: 1$)$ work-family conflict could influence subjective wellbeing directly $(\beta=-0.125, P<0.05) ; 2)$ work-family conflict could influence subjective well-being through job burnout (indirect effect was $\mathbf{- 0 . 1 9 7}$, total effect was $\mathbf{- 0 . 3 2 2}$ ), job burnout partially mediated the relation between work-family conflict and subjective well-being; 3 ) job burnout could influence subjective well-being directly $(\beta=-0.529, \mathrm{P}<0.001) ; 4)$ job salary and promotion satisfaction could influence subjective well-being through job burnout (indirect effect was 0.169) and reduced the burnouts' negative influence on subjective well-being, job burnout mediated the relation between job salary and promotion satisfaction and subjective well-being. Conclusion: We can enhance subjective well-being of primary and middle school principals through balancing work-family conflict, intervening job burnout, raising incomes, providing opportunities for career roles.
\end{abstract}

\section{Keywords}

Work-Family Conflict, Job Salary and Promotion Satisfaction, Job Burnout, Subjective Well-Being, Path Analysis

\footnotetext{
"Corresponding author.
}

How to cite this paper: Hu, C. M., Cui, S. J., \& He, H. M. (2016). Path Analysis of the Related Factors to Subjective Well-Being of Primary and Middle School Principals-Based on Job Demands-Resources Model. Psychology, 7, 335-344. 


\section{Introduction}

A principal, the soul of a school (Wang, 2012), is usually considered as the manager of school. The qualities for being a principal are constantly changing with the developing of society. It was pointed out in China's National Medium and Long-term Education Reform and Development Outline (2010) that educationalists would be cultivated and encouraged to manage schools. Thus, school principals' roles have oriented to a new direction that they would not only be managers of school but also be experts in education. There are ten requirements for being a qualified educationalist principal, including advanced educational thoughts, profound enthusiasm for education, high educational ideal, extensive knowledge about education, rich experience in education, awareness of doing scientific research, pragmatic leadership style, excellent communication skills, superb management art and excellent moral character (Xu, 2015).

As the social expectations and requirements for primary and middle school principals were constantly rising in China, their physical and mental health would also not be ignored. Individuals may feel happy only when they are healthy both physically and mentally. Happiness of a school principal will directly affect the development of school because one of principals' responsibilities is to help teachers to feel fulfilled at work (Yan, 2006). A principal with a sense of subjective well-being will spread positive mood to teachers and students and enhance the development of school (Weng, 2011). However, what factors related to work would affect the principals' happiness? This article will apply Job Demands-Resources Model and investigate the influence of work-family conflict, job salary and promotion satisfaction, and job burnout on subjective well-being of primary and middle school principals. We hope to give suggestions for enhancing principals’ subjective well-being.

\subsection{Job Demands-Resources Model (JD-R)}

JD-R considered that two kinds of categories, that is, job demands and job resources, existed at working conditions (Demerouti, Bakker, Nachreiner et al., 2001). Job demands refer to physical, psychological, social and organizational aspects demanded in a certain job for individuals, such as conflicts and stress, which individuals will pay a cost both physically or psychologically in order to obtain accomplishments and skills. Job resources refer to those physical, psychological, social and organizational aspects, such as income and organizational support, which facilitate individuals to reach goals in work and enhance individuals' development. Job resources reduce job demands, physical and psychological consumption also. Job demands and resources lead to two potential psychological processes in work, the one is health impairment process and the other is motivational process. Health impairment process refers to that individuals' physical and psychological exhaustion due to job demands, it may cause physical and mental health problems and employee demission. The motivational process refers to that job resources can improve the level of individual job involvement, strengthen work motivation and encourage excellent work performance. At present, JD-R has been applied extensively and verified in studies covering different professions in different countries (Wang \& Qin, 2009).

\subsection{Work-Family Conflict, Job Burnout and Subjective Well-Being}

Job burnout, the negative attitude and behaviors of individuals (Sang Qing-song, Huang, 2007), which includes three typical dimensions, that is, exhaustion, depersonalization and inefficacy. It is an exhaustion of body and mind, a kind of energy impairment in JD-R. Previous studies showed job burnout had negative impact on individual's subjective well-being (Yung \& Wen, 2014; Xie \& Zeng, 2011), which is an overall assessment of individual's quality of life as well as an important indicator of personal physical and mental status and quality of life (Yang, Fu, Zhao et al., 2015). Job burnout could cause exhaustion of individuals and undermine their subjective well-being, which is accorded with the health impairment process of JD-R.

Work-family conflict occurs when stress from work role and family role are incompatible (Duxbury \& Higgins, 1991). It is one of job demands for individuals. Previous researches indicated it could lead to job burnout and destruct individuals’ subjective well-being (Bouchard \& Poirier, 2011; Panatik, Badri, Rajab et al., 2011). Based on the job impairment process of JD-R and related researches, we proposed the following hypothesis.

Hypothesis 1: Job burnout could directly affect subjective well-being of principals in primary and middle school.

Hypothesis 2: Work-family conflict would directly affect the subjective well-being of principals in primary and middle school. 
Hypothesis 3: Job burnout would be an intermediate variable through which work-family conflict would affect subjective well-being.

\subsection{Job Salary and Promotion Satisfaction, Job Burnout and Subjective Well-Being}

Job satisfaction refers to individual's subjective responses to work situations based on comparison between the actual status and expectations for work (Cranny, Smith, \& Stone, 1992), including internal satisfaction, external satisfaction and general satisfaction for work. Internal satisfaction is individual's satisfaction with the characteristics of job, social status related to work. External satisfaction refers to individual's satisfaction with the promotion, salary, career development and so on. General satisfaction refers to individual's satisfaction with the internal and external situation, environment and interpersonal relationships in work (Weiss, Dawis, England et al., 1967). Job satisfaction is one of individuals' job resources.

Investigations on the job satisfaction of primary and middle school teachers in China revealed that the level of satisfaction for their work were high (Xu \& Zhao, 2012; Peng \& Liu, 2012) and internal satisfaction level was higher than external satisfaction level. In recent years, despite the increase of teachers' wages in China, their incomes were still relatively low (Luo \& Wang, 2011). Thus, some news showed that teachers in China were not satisfied with their incomes and prospects of work. For example, in 2014, teachers striked and protested against the low salary and issues related to their salary in Gushi in Henan Province (The China Youth Daily, 2014). In consequence, "injury of low incomes" for teachers in China is a problem that cannot be ignored (Li, 2015). Therefore, we mainly explored primary and secondary school principals' satisfaction with their salaries and promotion in work and its effects on their subjective well-being.

So far, most researchers who focused on studying JD-R considered the health impairment process and motivational process as two parallel processes and studied the influence of work resources and demands on impairment and motivation respectively (Li, Li, \& Tian, 2013). Some researchers discussed further on the basis of the model and put forward buffering hypothesis that job resources could buffer the effects of job demands (e.g., job burnout) on subjective well-being (Bakker, Demerouti, Taris et al., 2003; Bakker, Demerouti, \& Euwema, 2005). For example, when work resources are very abundant, job demands would not lead to health impairment (Bakker, Brummelhuis, Prins et al., 2011). Based on this hypothesis, we tried to figure out whether the job salary and promotion satisfaction would compensate for the impact of job burnout on subjective well-being.

Studies have found that the level of job satisfaction of vocational middle school teachers and civil servants had a positive correlation with subjective well-being significantly (Xian, Wang, \& Jing, 2011; Zheng \& Liu, 2012). It was also found that teachers' job satisfaction would affect their enthusiasm for work as well as their physical and mental health (Xu, 2012). Research also revealed that job satisfaction level of child welfare workers and hospital employees' was negatively and significantly correlated to job burnout (Lizano, Barak, 2015; Khalatbari, Ghorbanshiroudi, \& Firouzbakhsh, 2013). Teachers' job satisfaction could predict the level of job burnout (Tang \& Peng, 2008; Zhang, Yang, \& Ling, 2014). On the basis of existing researches, we proposed the following hypothesis:

Hypothesis 4: Job salary and promotion satisfaction would directly influence subjective well-being of primary and secondary school principals.

Hypothesis 5: Job burnout could be an intermediate variable through which job salary and promotion satisfaction would influence the subjective well-being.

Based on the analysis and hypothesis above, we constructed path analysis model on effect of work-family conflict, job salary and promotion satisfaction and job burnout on subjective well-being (Figure 1).

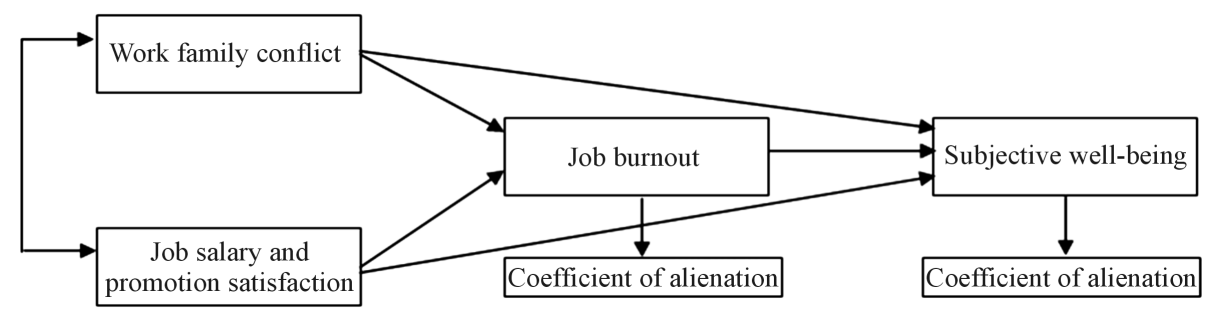

Figure 1. Hypothetical path analysis model on effect of work-family conflict, job salary and promotion satisfaction and job burnout on subjective well-being. 


\section{Methods}

\subsection{Participants}

Convenient sampling was used. Principals in primary and middle school who attended the national training programmes from January 2014 to April 2015 were selected to complete questionnaires in Chongqing of China. In total, 300 questionnaires were distributed and returned, among which 46 invalid questionnaires were removed for incomplete response and 254 valid questionnaires were left, with the effective rate of $84.7 \%$. Among those surveyed, 207 were male and 47 were female, the average age was $41.62 \pm 5.80$.

\subsection{Measures}

\subsubsection{General Well-Being Schedule (GWB)}

GWB (Wang, Wang, Ma et al., 1998) is composed of 33 items and is divided into 6 dimensions which include worries about health, vigor, life satisfaction and interests, sad or happy state of mind, control of emotions and behaviors, relaxation and stress. Because the items from 19 - 33 were used to measure the people who had the tendency of nervous breakdown, and the items from 1 - 18 had been used in China to measure the subjective well-being in many occupations. So, the items from 1 - 18 of this scale were chosen in this research as tools to measure the level of subjective well-being. The items 2, 5, 6, 7 used 5 points, with ranging from " 1 " representing "very bad" to " 5 " representing "very good". The other 14 items used 6 points, with ranging from " 1 " representing "extremely bad" to " 6 " representing "extremely good". 9 items were reversely scored, which included 1, 3, 6, 7, 9, 11, 13, 15, 16. Higher score indicates higher level of subjective well-being. In this study, the Cronbach's alpha of this scale was 0.837 .

\subsubsection{Work-Family Conflict (WFC)}

WFC (Zhou \& He, 2009) contains a total of 18 items and is divided into two dimensions, including "work to family conflict" and "family to work conflict". 5 points scale is used, with ranging from " 1 " representing "disagree" to " 5 " representing "agree completely". The higher the total score is, the stronger the work-family conflict is. In this study, the Cronbach's alpha of the scale was 0.884 .

\subsubsection{Job Salary and Promotion Satisfaction Survey (JSPSS)}

The scale (Spector, 1985; Xu, 2012) includes 30 items of four subscales which are job salary and promotion satisfaction, with benefits and rewards, with the work itself and with working conditions. In this study, the subscale on job salary and promotion satisfaction was used, which is composed of 11 items scored with 5 points, ranging from " 1 " representing "strongly disagree" to " 5 " representing "strongly agree". Higher total score represents higher level of job salary and promotion satisfaction. In this study, the Cronbach's alpha of the scale was 0.848 .

\subsubsection{Maslach Burnout Inventory-Educators Survey (MBI-ES)}

MBI-ES (Li, Shi, \& Luo, 2003), which is the most widely used in the study of teachers' occupational tiredness, contains 22 questions and three subscales. Three subscales are about exhaustion, depersonalization and inefficacy. 5 points score was adopted, with ranging from "1" representing "never" to " 5 " representing "always". Higher total score indicates more severe job burnout. In this study, the Cronbach's alpha of the scale was 0.866 .

\subsection{Statistical Analysis}

SPSS11.5 was used to input and process data. Various methods, including descriptive statistics, product-moment correlation, regression analysis, were adopted to analyze data.

\section{Results}

\subsection{Descriptive Statistics}

The means, standard deviations of all variables and correlation matrix were shown in Table 1. Subjective wellbeing had significant negative correlation with job burnout and work-family conflict. The correlation between subjective well-being and job salary and promotion satisfaction was significant positive. Job burnout had signif- 
icant positive correlation with work-family conflict, and significant negative correlation with job salary and promotion satisfaction. Work-family conflict had significant negative correlation with job salary and promotion satisfaction.

\subsection{Path-Analysis on the Effect of Work-Family Conflict, Job Salary and Promotion Satisfaction and Job Burnout on Subjective Well-Being}

Having found that work family conflict, job salary and promotion satisfaction, job burnout and subjective wellbeing were interrelated significantly, we adopted multiple regression analysis to explore the interrelationship path among them.

Regression analysis 1: In regression 1 (Table 2), work-family conflict was as independent variable and subjective well-being was as dependent variable. The results indicated work-family conflict could explain $17.8 \%$ of the variance of subjective well-being.

Regression analysis 2: In regression 2 (Table 3), job salary and promotion satisfaction was as independent variable and subjective well-being was as dependent variable. The results indicated job salary and promotion satisfaction could explain $13.8 \%$ of the variance of subjective well-being.

Regression analysis 3: In regression 3 (Table 4), job burnout was as independent variable and subjective well-being was as dependent variable. It was found that job burnout could explain $38.9 \%$ of the variance of subjective well-being.

Regression analysis 4: In regression 4 (Table 5), work-family conflict and job salary and promotion satisfaction were as independent variable and job burnout was as dependent variable. The results indicated that the two

Table 1. Descriptive statistics of variables $(\mathrm{N}=254)$.

\begin{tabular}{|c|c|c|c|c|c|c|}
\hline Variables & M & SD & 1 & 2 & 3 & 4 \\
\hline 1) job burnout & 54.88 & 9.62 & 1 & & & \\
\hline 2) work-family conflict & 49.72 & 13.02 & $0.509^{* *}$ & 1 & & \\
\hline 3) job salary and promotion satisfaction & 35.54 & 7.86 & $-0.479^{* *}$ & $-0.428^{* *}$ & 1 & \\
\hline 4) subjective well-being & 72.32 & 9.77 & $-0.624^{* *}$ & $-0.422^{* *}$ & $0.371^{* *}$ & 1 \\
\hline
\end{tabular}

Note: ${ }^{*}$ Refers to $\mathrm{P}<0.05 ;{ }^{* *}$ Refers to $\mathrm{P}<0.01 ;{ }^{* * *}$ Refers to $\mathrm{P}<0.001$.

Table 2. Regression analysis on impact of work-family conflict on subjective well-being.

\begin{tabular}{cccc}
\hline Variable & R2 & $\beta$ & F \\
\hline Work-family conflict & 0.178 & -0.422 & $54.587^{* * * *}$ \\
\hline
\end{tabular}

Table 3. Regression analysis on impact of job salary and promotion satisfaction on subjective well-being.

\begin{tabular}{cccc}
\hline Variable & R2 & $\beta$ & F \\
\hline Job salary and promotion satisfaction & 0.138 & 0.371 & $40.288^{* * *}$ \\
\hline
\end{tabular}

Table 4. Regression analysis on impact of job burnout on subjective well-being.

\begin{tabular}{cccc}
\hline Variable & R2 & $\beta$ & F \\
\hline Job burnout & 0.389 & -0.624 & $160.324^{* * *}$ \\
\hline
\end{tabular}

Table 5. Regression analysis on impact of work-family conflict, job salary and promotion satisfaction on job burnout.

\begin{tabular}{cccccc}
\hline Variables & $\mathrm{R} 2$ & $\mathrm{~F}$ & $\beta$ & $\mathrm{t}$ \\
\hline Job salary and promotion satisfaction & & & -0.320 & -5.652 \\
Work-family conflict & 0.343 & $64.437^{* * *}$ & 0.000 & 6.569 \\
\hline
\end{tabular}


independent variables could mutually explain $23.1 \%$ of the variance of job burnout. The influence coefficient with which job salary and promotion satisfaction impacted on job burnout was $-0.320(\mathrm{P}<0.000)$. The influence coefficient with which work-family conflict impacted on job burnout was $0.372(\mathrm{P}<0.000)$.

Regression analysis 5: In regression 5 (Table 6), work-family conflict, job salary and promotion satisfaction and job burnout were as independent variable and subjective well-being was as dependent variable.

The results indicated that the three independent variables could explain $40.7 \%$ of the variance of subjective well-being. The influence coefficient with which job salary and promotion satisfaction impacted subjective well-being was $0.064(\mathrm{P}>0.05)$. The influence coefficient with which work-family conflict affected subjective well-being was $-0.1254(\mathrm{P}<0.05)$. The influence coefficient with which job burnout impacted subjective well-being was $-0.529(\mathrm{P}<0.001)$.

According to the results of multiple regression analysis above, we came to the following conclusions.

In regression analysis 1,3 and 5 , the $\beta$ values of work-family conflict were respectively $-0.422,0.372$ and -0.125 , they were all significant statistically. What's more, comparing the regression analysis 1 with the regression analysis 5 , there was a change of $\beta$ value from -0.422 to -0.125 . We could infer that work-family conflict would not only directly influence subjective well-being but also indirectly affect the subjective well-being partly through job burnout.

In regression analysis 3 and 5 , the $\beta$ values of job burnout were respectively -0.624 and -0.529 , they were both significant statistically. Also, there was a change of $\beta$ value from -0.624 to -0.529 , showing that the direct effect of job burnout on subjective well-being was reduced by the influence of job salary and promotion satisfaction.

In regression analysis 2 and 4 , the $\beta$ values of job salary and promotion satisfaction were respectively 0.371 and -0.320 , they were both significant statistically. However, the $\beta$ value of job salary and promotion satisfaction in regression analysis 5 was 0.064 and turned to be insignificant statistically. That change indicated that job salary and promotion satisfaction influenced subjective well-being completely through the mediation effect of job burnout.

Based on the analysis about the results, the path analysis model was drawn (Figure 2).

From Figure 2, we can see four paths influencing subjective well-being were significant statistically. 1) Work-family conflict would directly influence subjective well-being, with the direct effect coefficient of -0.125 $(\mathrm{P}<0.05) .2)$ Work-family conflict would indirectly impact subjective well-being through the mediation effect of job burnout. Job burnout has partial mediating effects on the relation between work-family conflict and subjective well-being. The indirect effect coefficient with which work-family conflict affected subjective well-being was $0.197(-0.529 \times 0.372)$, and the total effect coefficient was $-0.322((-0.125)+(-0.197)) .3)$ Job burnout

Table 6. Regression analysis on impact of work-family conflict, job salary and promotion satisfaction, job burnout on subjective well-being.

\begin{tabular}{ccccc}
\hline Variables & R2 & F & $\beta$ & Sig. \\
\hline Job salary and promotion satisfaction & & & 0.064 & 1.119 \\
Work-family conflict & 0.407 & $57.091^{* * *}$ & -0.125 & -2.145 \\
Job burnout & & & -0.529 & -8.805 \\
\hline
\end{tabular}

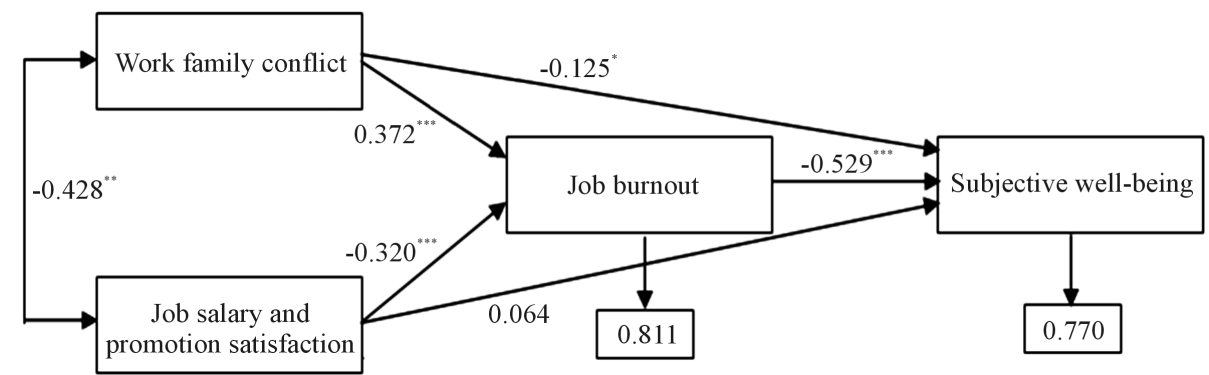

Figure 2. Path analysis model on effect of work family conflict, job salary and promotion satisfaction and job burnout on subjective well-being. 
would directly influence subjective well-being, with the direct effect coefficient of $-0.529(\mathrm{P}<0.001)$. 4) Job salary and promotion satisfaction would indirectly impact subjective well-being through job burnout, which played a completely mediating role on the relation between job salary and promotion satisfaction and subjective well-being. Job salary and promotion satisfaction indirectly affected subjective well-being, with the indirect effect coefficient of $0.169(-0.529 \times-0.320)$. In conclusion, the hypothesis $1,2,3$ and 5 were verified and the hypothesis 4 was proved to be false. Consequently, job salary and promotion satisfaction does not directly affect subjective well-being and job burnout is mediating variable through which work-family conflict and job salary and promotion satisfaction influence subjective well-being.

\section{Discussion}

\subsection{The Effect of Work-Family Conflict on Subjective Well-Being}

As it was shown in the results, work-family conflict and subjective well-being were significant negatively correlated and the former could negatively predict the latter. Therefore, the subjective well-being of principals' in primary and secondary school will be getting lower if their work-family conflict gets more severe. Work-family conflict is a reason for influencing subjective well-being, which were accorded with the results of previous researches on primary and secondary school teachers (Li, 2011; Liu, Feng, \& Liu, 2010; Panatik, Badri, Rajab et al., 2011). In Chinese traditional culture, harmonious relationship is a major presentation of individual happiness. It was possible for principals in primary and secondary school to create good working environment and harmonious family atmosphere at the same time if they could handle work-family conflict well and further reduce the negative conflict between work and family. On the contrary, if work-family conflict were too serious, the efficiency of their work would decline and also their family relationship would be injured, thus subjective well-being would be reduced.

\subsection{The Effect of Job Salary and Promotion Satisfaction on Subjective Well-Being}

The research results showed that there were significant negative correlations between job salary and promotion satisfaction and subjective well-being. Higher job salary and promotion satisfaction corresponded with better subjective well-being of primary and secondary school principals. That is consistent with the results of previous researches about secondary vocational teachers and civil servants (Xian, Wang, \& Jing, 2011; Zheng \& Liu, 2012). But it would be noticeable that job salary and promotion satisfaction would not directly affect their subjective well-being. At present, the prevailing outlook of "worship of materialism, money is king" had become a cancer of mind in society and a lot of people considered that money can directly promote happiness. Conversely, this study proved money was not the direct cause of individual subjective well-being.

\subsection{Job Burnout Is Mediating Variable through Which Work-Family Conflict as Well as Job Salary and Promotion Satisfaction Influence Subjective Well-Being}

The study found that job burnout partly played an intermediate role in the influence of work-family conflict on subjective well-being, which is consistent with existing researches (Lewig, Xanthopoulou, Bakker et al., 2007; Hakanen, Bakker, \& Schaufeli, 2006; Yang, Fu, Zhao et al. 2015). It showed that work-family conflict couldn’t only directly influence subjective well-being of primary and secondary school principals but also indirectly impact their subjective well-being through influencing job burnout. That verified the impairment process of JD-R. Primary and secondary school principals had to pay physical or mental costs to cope with work-family conflict which might cause negative mood, a low sense of achievement on work and then lead to impairment of body and mind. Thus, their overall feeling of quality of life would be affected and the subjective well-being would be declined.

It was also found in this study that job burnout played a completely intermediate role in the influence of job salary and promotion satisfaction on subjective well-being. According to this, despite of not having direct impact on subjective well-being, job salary and promotion satisfaction would impact subjective well-being through influencing job burnout. Besides, job salary and promotion satisfaction reduced the negative effect of job burnout on subjective well-being, the results were consistent with previous research (Bakker, Demerouti, \& Euwema, 2005). Higher incomes could provide a wealthier life for families and alleviate economic pressures. Meanwhile, expected opportunities for promotion could enhance individuals' expectations and enthusiasm for work. 
All these helped to mitigate their job burnout and improve their subjective well-being. The results leaded to a further concern for us that job salary and promotion satisfaction, as a kind of work resources, could also affect the impairment process of work. Job salary and promotion satisfaction, which is different from work demand, could effectively alleviate exhaustion of individual body and mind, and decrease negative performance in the work, furthermore, improve individual's work efficiency as well as physical and mental health.

\subsection{The Value of This Study}

Based on the previous research on JD-R, this research explored the influencing path of work family conflict, job salary and promotion satisfaction and job burnout on subjective well-being. The research has following values: 1) Verifying the health impairment process. Work-family conflict would aggravate job burnout of primary and secondary school principals, leading to the reduction of subjective well-being. It was fit with the health impairment process, that is, work demands may lead to depletion and then to physical and psychological problems or even an inclination of quitting the job. 2) Work resources would affect the health impairment process. It was found in this study that work demands would aggravate job burnout while work resources would alleviate job burnout and affect individuals' subjective well-being. 3) A new perspective for future research on JD-R was put forward from the results. Work of individuals could not be utterly separated with their family, physical and mental health. Job resources and demands could not only influence working effectiveness but also influence physical and mental health and families. Most of the previous researches about JD-R focused on influence of job resources and demands on individuals' work performance, however, few researches investigated the effect of job resources and demands on individuals' physical and mental health. In this study we found that job resources and demands would enhance subjective well-being through decreasing job burnout. Therefore, in future study, we should further explore the effect of job resources and demands on individuals' physical and psychological health (such as sleep quality, psychological pressure, etc.).

Based on this research, we can improve subjective well-being of primary and secondary school principals through the following aspects. 1) Balancing work-family conflict. Effective measures should be taken to reduce work-family conflict, such as flexible working hours, telecommuting, improvement of performance appraisal, providing social support and so on (Yang, Fu, Zhao et al., 2015; Brough \& O’Driscoll, 2010). 2) Decreasing job burnout. We should help principals to handle skills of mental health and reduce their job burnout by themselves. 3) Raising salary to an appropriate level. According to working conditions of principals of the primary and secondary school, it is necessary to adjust their salary to an appropriate level so that they feel their work is reasonably paid. For primary and secondary school principals, raising the level of compensation does not only mean the increase of money but also means their work is recognized and respected by society and educational departments. Therefore, it can effectively reduce their job burnout and enhance their enthusiasm for work. 4) Creating development opportunities. Educational department should provide various learning opportunities, such as training, study tours and so on, to improve professional capacity of primary and secondary school principals and enhance their comprehensive abilities so that they can be well competent for their jobs.

\section{Orientation for Future Research}

This study investigated how the job salary and promotion satisfaction, one of job resources, influenced the impairment process. Then, besides satisfaction with work, would other job resources also affect the impairment process? That is worth further researching in the future. Also, it was found in this study that job resources could affect the impairment process. Then, would job demands also affect motivational process? Would the impairment process and motivational process have an influence with each other? It is worth deeper thinking. In future study we should further test JD-R and do some revisions with the model according to research findings.

\section{References}

Bakker, A. B., Brummelhuis, L. L., Prins, J. T. et al. (2011). Applying the Job Demands-Resources Model to the WorkHome Interface: A Study among Medical Residents and Their Partners. Journal of Vocational Behavior, 79, 170-180. http://dx.doi.org/10.1016/j.jvb.2010.12.004

Bakker, A. B., Demerouti, E., \& Euwema M. C. (2005). Job Resources Buffer the Impact of Job Demands on Burnout. Journal of Occupational Health Psychology, 10, 170-180. http://dx.doi.org/10.1037/1076-8998.10.2.170

Bakker, A. B., Demerouti, E., Taris, T. et al. (2003). A Multi-Group Analysis of the Job Demands-Resources Model in Four 
Home Care Organizations. International Journal of Stress Management, 10, 16-38. http://dx.doi.org/10.1037/1072-5245.10.1.16

Bouchard, G., \& Poirier, L. (2011). Neuroticism and Well-Being among Employed New Parents: The Role of the WorkFamily Conflict, Personality and Individual Differences. 2011, 50, 657-661. http://dx.doi.org/10.1016/j.paid.2010.12.012

Brough, P., \& O’Driscoll, M. P. (2010). Organisational Interventions for Balancing Work and Home Demands: An Overview. Work \& Stress, 24, 280-297. http://dx.doi.org/10.1080/02678373.2010.506808

Cranny, C. J., Smith, C. P., \& Stone, E. F. (1992). Job Satisfaction: How People Feel about Their Jobs and How It Affects Their Performance. San Francisco: New Lexington Press.

Demerouti, E, Bakker, A. B., Nachreiner, F. et al. (2001). The Job Demands-Resources Model of Burnout. Journal of Applied Psychology, 86, 499-512. http://dx.doi.org/10.1037/0021-9010.86.3.499

Duxbury, L. E., \& Higgins, C. A. (1991). Gender Difference in Work-Family Conflict. Journal of Applied Psychology, 76, 60-74. http://dx.doi.org/10.1037/0021-9010.76.1.60

Hakanen, J. J., Bakker, A. B., \& Schaufeli, W. B. (2006). Burnout and Work Engagement among Teachers. Journal of School Psychology, 43, 495-513. http://dx.doi.org/10.1016/j.jsp.2005.11.001

Khalatbari, J., Ghorbanshiroudi, S., \& Firouzbakhsh, M. (2013). Correlation of Job Stress, Job Satisfaction, Job Motivation and Burnout and Feeling Stress. Procedia-Social and Behavioral Sciences, 84, 860-863. http://dx.doi.org/10.1016/j.sbspro.2013.06.662

Lewig, K. A., Xanthopoulou, D., Bakker, A. B. et al. (2007). Burnout and Connectedness among Australian Volunteers: A Test of the Job Demands-Resources Model. Journal of Vocational Behavior, 71, 429-445. http://dx.doi.org/10.1016/j.jvb.2007.07.003

Li, C. P., Shi, K., \& Luo, Z. X. (2003). An Investigation on Job Burnout of Doctor and Nurse. Chinese Journal of Clinical Psychology, 11, 216-217.

Li, X. S. (2011). The Relationship between Work-Family Conflict and Subjective Well-Being: The Adjustment Function of Work-Family Support. Vocational \& Technical Education Forum, 24, 23-25.

Li, Z. H. (2015). The teachers' Injury of Low Income. People's Education, 2, 10.

Li, Z. H., Li, Q. L., \& Tian, Y. H. (2013). The Impact of Work Engagement on Emotional Exhaustion-An Analysis from the Perspective of Job Demands-Resources Model. Soft Science, 27, 103-107.

Liu, W., Feng, J. X., \& Liu M. (2010). On Senior High School Teachers’ Work-Family Conflicts: Their Characteristics and Their Impact on the Teachers' Satisfaction with Their Life. Chinese Journal of Special Education, 3, 77-81.

Lizano, E. L., \& Barak, M. M. (2015). Job Burnout and Affective Wellbeing: A Longitudinal Study of Burnout and Job Satisfaction among Public Child Welfare Workers. Children and Youth Services Review, 55, 18-28. http://dx.doi.org/10.1016/j.childyouth.2015.05.005

Luo, R. G., \& Wang, S. S. (2011). Study on the Primary and Middle School Teachers' Job Salary Satisfaction. Modern Education Management, 5, 75-78.

Panatik, S. A. B., Badri, S. K. Z., Rajab, A., Rahman, H. A., \& Shah, I. M. (2011). The Impact of Work-Family Conflict on Psychological Well-Being among School Teachers in Malaysia. Procedia-Social and Behavioral Sciences, 29, $1500-1507$. http://dx.doi.org/10.1016/j.sbspro.2011.11.390

Peng, W. B., \& Liu, D. Z. (2012). Research on the Relationship of Working Satisfaction Degree and Teaching Motivation in Elementary and Secondary School Teachers. Psychological Development and Education, 6, 611-617.

Sang, Q. S., \& Huang, W. M. (2007). Study on Job Burnout of Primary and Middle School Teachers in Rural Areas. Chinese Journal of Public Health, 23, 1260-1261.

Spector, P. (1985). Measurement of Human Service Staff Satisfaction: Development of the Job Satisfaction Survey. American Journal of Community Psychology, 13, 693-713. http://dx.doi.org/10.1007/BF00929796

Tang, F. G., \& Peng, Y. (2008). Relation between University Teachers’ Burnout and Job Satisfaction and Social Support. Chinese Journal of Public Health, 24, 930-932.

The China Youth Daily (2014). Hunderds of Teachers Asked for Salary in Gushi in Henan Province. 25 December 2014. http://zqb.cyol.com/html/2014-12/25/nw.D110000zgqnb_20141225_7-01.htm

Wang, T. J. (2012). Study Xing-Zhi Tao, Be a Principal with Heart. China Education Daily, 7-3(6).

Wang, X. D., Wang, X. L., Ma, H., et al. (1998). Handbook of Rating Scales for Mental Health (Revised). Chinese Mental Health Journal, No. 12, 173-178.

Wang, Y. F., \& Qin, J. L. (2009). Integrated Study of Job Burnout and Work Engagement. Advances in Psychological Science, 17, 802-810.

Weiss, D., Dawis, R., England, G., \& Lofquist, L. H. (1967). Manual for the Minnesota Satisfaction Questionaire. Minneap- 
olis, MN: Industrial Relations Center, University of Minnesota.

Weng, Q. Y. (2011). A Discourse on the Secondary School Principal's Sense of Occupational Well-Being. Teacher Education Research, 23, 17-20.

Xian, G. C., Wang, Y., \& Jing, J. X. (2011). Relationship between Job Satisfaction and Subjective Well-Being of Secondary Vocational School Teachers. Vocational \& Technical Education Forum, 36, 83-86.

Xie, R., \& Zeng, X. Y. (2011). Easing the Preschool Teachers’ Occupational Languor and Enhancing Their Feelings of Occupational Well-Being. Studies in Preschool Education, 6, 67-69.

$\mathrm{Xu}, \mathrm{H}$. (2015).Ten Qualities of Educator's Primary and Middle School Principals, Based on Perspective of Famous Principals at Home and Abroad. Journal of Inner Mongolia Normal University (Educational Science), 28, 87-89.

$\mathrm{Xu}$, Y. H. (2012). Exploring the Impact of Teachers' Job Satisfaction of Elementary and Middle School and Organizational Culture on School Development-The Positive Study Based on the 299 Teacher of Elementary and Middle School in Lujiang Town of Anhui Province. Master's Thesis, Suzhou: Soochow University.

Xu, Z. Y., \& Zhao, Z. H. (2012). An Empirical Study of Job Satisfaction of Beijing Primary School Teachers. Teacher Education Research, 24, 85-92.

Yan, W. Y. (2006). Role of Principals: Creating Teachers’ Vocational Happiness. Research in Education Development, 6, 73-74.

Yang, L., Fu, C., Zhao, X., Chen, L., Yan, H.-L., \& Zhang, Y. (2015). Mediating Effect of Job Burnout on the Relationship between Work-Family Conflict and Subjective Well-Being of Primary and Middle School Teachers. Chinese Journal of Clinical Psychology, 23, 330-335.

Zhang, J. R., Yang, Z. G., \& Ling, H. (2014). Work Stress, Job Satisfaction and Job Burnout in Primary and Middle Schools Teachers. Chinese Journal of Clinical Psychology, 22, 920-922.

Zheng, Y., \& Liu, W. (2012). Relationship among Job Satisfaction, Subjective Well-Being and Job Performance. Research on Financial and Economic Issues, 12, 23-30.

Zhou, C. M., \& He, X. C. (2009). The Relationship between Work-Family Conflict and Life Satisfaction: Big Five Personality as a Mediator Variable. Psychological Science, 32, 1057-1060. 